\title{
FRAÇÃO GÉRMEN COM PERICARPO DE MILHO NA ALIMENTAÇÃO HUMANA: QUALIDADE NUTRICIONAL E APLICAÇÃO TECNOLÓGICA ${ }^{1}$
}

\author{
Maiza Vieira Leão de Castro $^{2}$, Aline Luiz de Mendonça ${ }^{2}$, Grazielle Gebrim Santos², \\ Luciana de Oliveira Froes ${ }^{2}$, Jullyana Borges de Freitas ${ }^{3}$, Maria Margareth Veloso Naves ${ }^{4}$
}

\section{ABSTRACT \\ GERM FRACTION WITH MAIZE \\ PERICARP AS FOOD: NUTRITIONAL QUALITY AND TECHNOLOGICAL APPLICATION}

The germ fraction with maize pericarp (GMP), obtained from the degermination of this cereal, presents a high nutrient density, however, it is underused as food. Therefore, the objective of this study was to develop cookies enriched with GMP, in order to evaluate their acceptability and determine their centesimal composition. The GMP fraction was added to the formulations, in the proportion of $40 \%$ and $50 \%$, in replacement of wheat flour and cassava starch. Centesimal composition analyses were performed for both the GMP fraction and cookies. All cookies were accepted, in relation to global acceptance, however, only the cookie with $40 \%$ replacement of wheat flour and cassava starch by GMP was accepted, concerning appearance. The GMP fraction showed high levels of lipids (18\%) and total dietary fiber $(29 \%)$, and considerable protein content (12\%). Significant differences were observed in the protein content of the cookie with $50 \%$ replacement of wheat flour and cassava starch by GMP

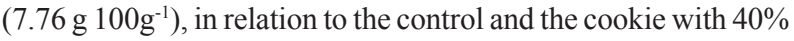

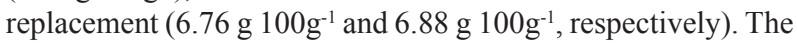
GMP fraction increased the dietary fiber content, did not change the lipids concentration, and reduced the energy value of cookies. The use of germ fraction with maize pericarp in food products allows the increase of their dietary fiber content and the decrease of their energy value.

KEY-WORDS: Zea mays L.; cookie; chemical composition; nutritional value; acceptability.

\section{INTRODUÇÃO}

O milho é um produto que ocupa posição importante na economia global, sendo o segundo cereal mais produzido no mundo. Do total da produção mundial, $70 \%$ a $85 \%$ do milho são destinados à

\section{RESUMO}

A fração gérmen com pericarpo de milho (GPM), obtida por meio da degerminação deste cereal, possui alta densidade de nutrientes, contudo, ainda é subutilizada na alimentação humana. Portanto, este trabalho teve como objetivos desenvolver biscoitos tipo cookie, enriquecidos com GPM, avaliar a aceitabilidade e determinar sua composição centesimal. A fração GPM foi acrescentada às formulações, na proporção de $40 \%$ e $50 \%$, em substituição à farinha de trigo e fécula de mandioca. Foram realizadas análises de composição centesimal da fração GPM e dos biscoitos. Todos os biscoitos foram aceitos, em relação à aceitação global, porém, apenas o biscoito com $40 \%$ de substituição de farinha de trigo e fécula de mandioca por GPM foi aceito, em relação à aparência. $\mathrm{Na}$ fração GPM, constataram-se altos teores de lipídios (18\%) e de fibra alimentar total (29\%), e conteúdo considerável de proteína (12\%). Foram observadas diferenças significativas no teor de proteínas do biscoito com $50 \%$ de substituição de farinha de

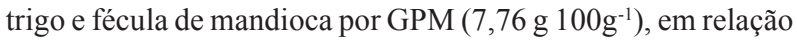

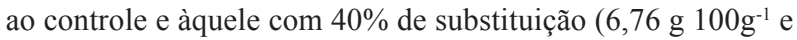

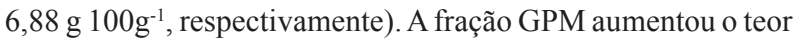
de fibra alimentar, não interferiu na concentração de lipídios e reduziu o valor energético dos biscoitos. O emprego da fração gérmen com pericarpo de milho, em produtos alimentícios, possibilita aumento do teor de fibra alimentar e redução do valor energético dos produtos.

PALAVRAS-CHAVE: Zea mays L.; biscoito; composição química; valor nutricional; aceitabilidade.

alimentação animal (Paes 2006). No Brasil, 4\% do milho produzido é consumido diretamente e $10 \%$ é utilizado por indústrias alimentícias, que transformam os grãos, a partir dos processos de moagem úmida ou moagem seca, gerando diversos produtos, tais como amido, farinhas, canjica, flocos de milho,

1. Trabalho recebido em abr./2010 e aceito para publicação em maio/2011 (nº registro: PAT 9659/ DOI: 10.5216/pat.v41i2.9659).

2. Universidade Federal de Goiás (UFG), Escola de Agronomia e Engenharia de Alimentos, Goiânia, GO, Brasil.

E-mails:maizavlc@yahoo.com.br, flordocerrado@gmail.com, grazinutrirte@gmail.com, lurwen@gmail.com.

3. Instituto Federal de Educação, Ciência e Tecnologia de Goiás (IFG), Departamento de Áreas Acadêmicas I, Goiânia, GO, Brasil.E-mail: jullyananut@yahoo.com.br.

4. Universidade Federal de Goiás (UFG), Faculdade de Nutrição, Laboratório de Nutrição Experimental, Goiânia, GO, Brasil.E-mail: mnaves@fanut.ufg.br. 
óleo e xaropes, e subprodutos, como o gérmen de milho, dentre outros (Alexander 1999, Paes 2006).

O grão de milho é composto por quatro estruturas principais: pericarpo (casca), endosperma, gérmen (embrião) e ponta. A fração gérmen com pericarpo é obtida a partir do processo de degerminação do grão de milho, no qual é separada do endosperma amiláceo, por maceração ou por atrito mecânico (Alexander 1999). Por possuir, em sua composição, teores elevados de lipídios, proteínas e fibras, esta fração é largamente utilizada como ingrediente, na elaboração de ração animal (Brito et al. 2005).

Além da alta densidade dos referidos nutrientes, a fração gérmen com pericarpo de milho contém proteínas com melhor perfil aminoacídico e, portanto, melhor qualidade nutricional, em relação às proteínas do grão inteiro (Wilson 1999, Brito et al. 2005, Naves et al. 2011). Assim, o uso deste subproduto, para fins de alimentação humana, inclusive na formulação de biscoitos tipo cookie, é uma alternativa para agregar valor a esta matéria-prima e, por outro lado, melhorar a qualidade nutricional de biscoitos (Palomar et al. 1994, Giami et al. 2005).

Em decorrência das propriedades funcionais das fibras alimentares, os incentivos para o desenvolvimento e comercialização de produtos com maior teor deste nutriente têm se intensificado (Colli et al. 2005). Neste sentido, justifica-se o emprego da fração gérmen com pericarpo de milho na alimentação humana, na forma de alimentos processados, uma vez que esta fração do grão de milho contém cerca de $30 \%$ de fibra (Naves et al. 2011).

Considerando-se a composição em nutrientes da fração gérmen com pericarpo de milho e as novas tendências alimentares, em busca de alimentos mais nutritivos e saudáveis, este trabalho teve os objetivos de desenvolver biscoitos tipo cookie, enriquecidos com a fração gérmen com pericarpo de milho, e analisar a aceitabilidade e a composição química centesimal dos biscoitos.

\section{MATERIAL E MÉTODOS}

Obtenção da amostra de gérmen com pericarpo de milho

A fração gérmen com pericarpo de milho (GPM) foi obtida na indústria Milhão Alimentos Ltda., localizada na cidade de Inhumas (GO), conforme descrito na Figura 1.

\section{Formulação dos biscoitos tipo cookie}

Os cookies foram elaborados em 2010, segundo formulação padronizada por Soares Júnior et al. (2007), com a redução da concentração de sal de $1 \%$ para $0,33 \%$, em função do resultado de testes sensoriais preliminares, que evidenciaram o gosto salgado na formulação original. Todos os demais ingredientes da formulação básica foram mantidos, uma vez que se pretendia avaliar a substituição da farinha de trigo e da fécula de mandioca pela fração gérmen com pericarpo de milho, em biscoitos já considerados aceitos. O biscoito controle (BC) foi preparado a partir de massa constituída de açúcares cristal e mascavo, margarina, ovo, essência de baunilha, farinha de trigo, fécula de mandioca, sal e fermento em pó, nesta ordem de adição. Na elaboração dos biscoitos-teste, a farinha de trigo e a fécula de mandioca foram substituídas pela fração GPM, nas proporções de $40 \%\left(\mathrm{BG}_{40}\right)$ e $50 \%\left(\mathrm{BG}_{50}\right)$ (Tabela 1$)$. A proporção máxima de substituição da farinha de trigo e da fécula de mandioca por GPM foi de 50\%, pois, em testes preliminares, observou-se que, acima

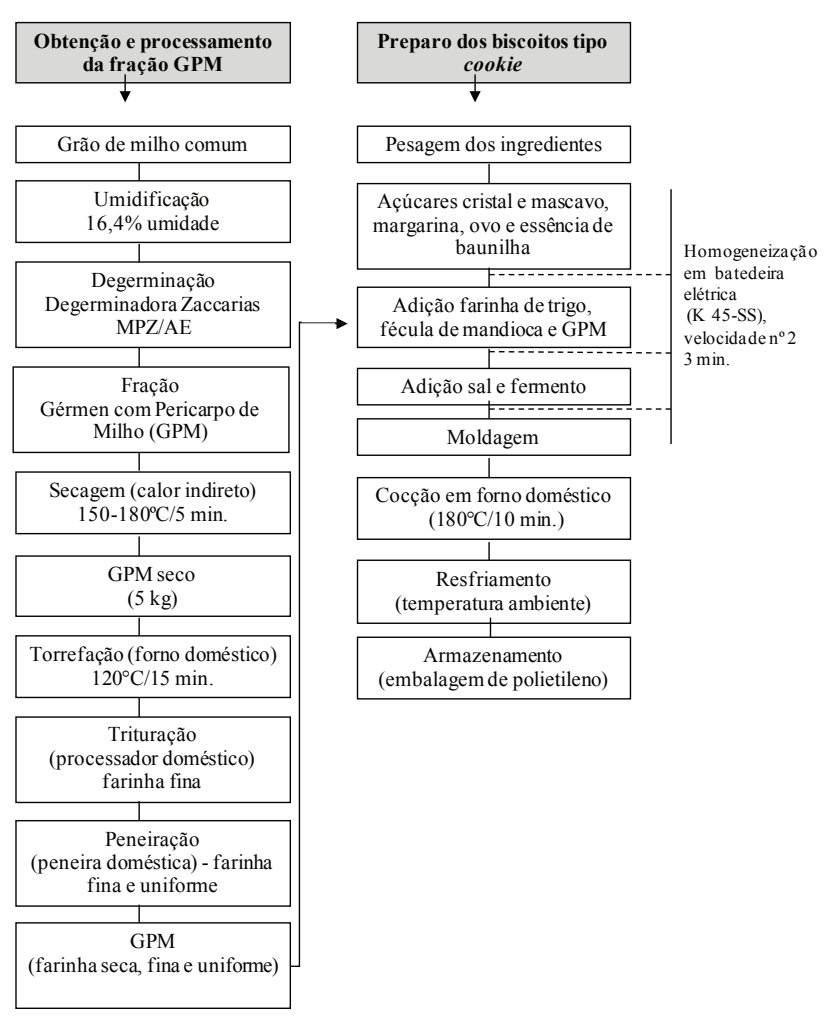

Figura 1. Fluxograma das etapas de obtenção da fração gérmen com pericarpo de milho (GPM) e de preparo dos biscoitos tipo cookie (Goiânia, GO, 2010). 
Tabela 1. Formulações de biscoitos com diferentes teores de gérmen com pericarpo de milho (GPM), em substituição à farinha de trigo e à fécula de mandioca (Goiânia, GO, 2010).

\begin{tabular}{|c|c|c|c|}
\hline \multirow{2}{*}{ Ingrediente } & \multicolumn{3}{|c|}{$\begin{array}{c}\text { Formulação do biscoito }^{1} \\
\text { quantidade }(\mathrm{g})\end{array}$} \\
\hline & $\mathrm{BC}$ & $\mathrm{BG}_{40}$ & $\mathrm{BG}_{50}$ \\
\hline Açúcar cristal & 183,3 & 183,3 & 183,3 \\
\hline Açúcar mascavo & 83,3 & 83,3 & 83,3 \\
\hline Margarina & 200,0 & 200,0 & 200,0 \\
\hline Ovo & 93,3 & 93,3 & 93,3 \\
\hline Baunilha & 3,3 & 3,3 & 3,3 \\
\hline Farinha de trigo & 281,7 & 169,3 & 141,2 \\
\hline Fécula de mandioca & 141,8 & 84,9 & 70,6 \\
\hline GPM & 0,0 & 169,3 & 211,7 \\
\hline Sal & 3,3 & 3,3 & 3,3 \\
\hline Fermento em pó & 10,0 & 10,0 & 10,0 \\
\hline Total (g) & $1.000,0$ & $1.000,0$ & $1.000,0$ \\
\hline
\end{tabular}

desta proporção, os biscoitos ficavam muito duros e escuros, perdendo as características tecnológicas de biscoitos tipo cookie. Em contrapartida, optou-se pela substituição mínima de $40 \%$, pois concentrações de GPM inferiores a $17 \%$, no biscoito (Tabela 1), não apresentavam as características sensoriais da fração GPM. As etapas do processamento dos biscoitos estão descritas na Figura 1.

\section{Teste de aceitação}

Os cookies foram submetidos aos testes de aceitação global e de aparência, mediante o uso de escala hedônica estruturada de 1 a 9 pontos (1 - desgostei muitíssimo; 9 - gostei muitíssimo). O intervalo dos escores 6 a 9 foi considerado como região de aceitação e o intervalo dos escores 1 a 4 como região de rejeição do produto. $\mathrm{O}$ escore 5, ponto intermediário, foi considerado como ponto de indecisão. $\mathrm{O}$ teste foi conduzido em laboratório, com 40 provadores não treinados, adultos, de ambos os sexos, recrutados entre os alunos e os servidores da Faculdade de Nutrição da Universidade Federal de Goiás (UFG), que assinaram um termo de consentimento livre e esclarecido. Para o teste de aceitação global, as amostras dos biscoitos foram servidas em pratos de fundo branco, codificadas com números de três dígitos, sob luz vermelha e em cabines individuais (Faria \& Yotsuyanagi 2002). Para a análise da aparência, as amostras foram apresentadas em pratos de fundo branco, codificadas com números de três dígitos e dispostas sobre mesa retangular, fora das cabines, sob luz natural. O projeto desta pesquisa foi aprovado pelo Comitê de Ética em Pesquisa da UFG (Protocolo COEP n 182/2009).

\section{Determinação da composição centesimal}

O teor de proteína do gérmen com pericarpo de milho e dos biscoitos tipo cookie foi determinado por meio da análise do nitrogênio total, pelo método de micro-Kjeldahl (AOAC 1990), empregando-se o fator 6,25, para conversão do nitrogênio em proteína bruta (FAO 1970). Os teores de lipídios das amostras foram determinados pelo método descrito por Bligh \& Dyer (1959). As concentrações de umidade, cinzas e fibra alimentar total (solúvel e insolúvel) foram determinadas segundo AOAC (1990). Os carboidratos foram estimados por diferença, subtraindo-se de cem os valores obtidos para proteínas, lipídios, umidade, cinzas e fibra alimentar. O Valor Energético Total (VET) do gérmen com pericarpo de milho, assim como dos biscoitos, foi determinado segundo Merril \& Watt (1973).

\section{Análise estatística}

Os dados do teste de aceitação e das análises de composição centesimal foram submetidos a análise de variância (ANOVA) e teste de comparação de médias (Tukey, a 5\%). Os cálculos estatísticos foram feitos com auxílio do programa STATISTICA Version 7.0 (StatSoft, Inc., Tulsa, OK, USA).

\section{RESULTADOS E DISCUSSÃO}

\section{Aceitabilidade dos biscoitos tipo cookie}

Os biscoitos testados obtiveram escores médios inferiores ao do biscoito controle (BC), para aceitação global e aparência. Em relação à aceitação global, todos os tratamentos foram aceitos, sendo que, pelo menos $80 \%$ dos provadores aceitaram os biscoitos $\mathrm{BG}_{40}$ e $\mathrm{BG}_{50}$, atribuindo valor igual ou superior a 6 (gostei levemente), não havendo diferenças significativas entre estes tratamentos (Tabela 2). 
Tabela 2. Aceitabilidade de biscoitos tipo cookie, produzidos com diferentes teores de gérmen com pericarpo de milho (GPM) (Goiânia, GO, 2010).

\begin{tabular}{|c|c|c|c|c|}
\hline \multirow[b]{2}{*}{ Biscoito $^{1}$} & \multicolumn{2}{|c|}{ Aceitação global } & \multicolumn{2}{|c|}{ Aparência } \\
\hline & Média $^{2}$ & $\begin{array}{c}\text { Aceitação } \\
(\%)\end{array}$ & Média $^{2}$ & $\begin{array}{c}\text { Aceitação }{ }^{3} \\
(\%)\end{array}$ \\
\hline $\mathrm{BC}$ & $7,88 \pm 1,02 \mathrm{a}$ & 100,0 & $6,88 \pm 1,32 a$ & 85,0 \\
\hline $\mathrm{BG}_{40}$ & $6,98 \pm 1,42 b$ & 82,5 & $6,20 \pm 1,65 b$ & 75,0 \\
\hline $\mathrm{BG}_{50}$ & $6,58 \pm 1,55 b$ & 80,0 & $4,53 \pm 1,69 c$ & 22,5 \\
\hline
\end{tabular}

${ }^{1} \mathrm{BC}$ : biscoito controle ( $0 \%$ de adição de $\left.\mathrm{GPM}\right)$; $\mathrm{BG}_{40}$ : biscoito com $40 \%$ de substituição de farinha de trigo e fécula de mandioca por GPM; $\mathrm{BG}_{50}$ : biscoito com $50 \%$ de substituição de farinha de trigo e fécula de mandioca por GPM.

${ }^{2} \mathrm{Os}$ valores constituem médias \pm desvios-padrão de 40 julgamentos. Em uma mesma coluna, médias com letras iguais não apresentam diferenças significativas, pelo teste Tukey, a $5 \%$.

${ }^{3}$ Aceitação: percentual de provadores que atribuíram escores iguais ou superiores a 6.

A formulação $\mathrm{BG}_{40}$ foi aceita, em relação à aparência, contudo, o aumento do teor de GPM no biscoito $\mathrm{BG}_{50}$ afetou, negativamente, a aparência do produto, que não foi aceito pelos provadores (Tabela 2). Isto pode ser explicado em razão da alta quantidade de fibra presente na fração GPM, o que dificultou a homogeneização da massa e a consequente padronização do formato dos biscoitos. Além disto, a adição de gérmen com pericarpo de milho promoveu o escurecimento dos biscoitos, o que pode ter interferido na aceitabilidade do produto (Buck et al. 1987). Jeltema et al. (1983) observaram que, quanto maior a substituição de farinha de trigo por fibra de milho, mais escuros ficam os biscoitos obtidos.

Sendo assim, o biscoito $\mathrm{BG}_{40}$ foi aceito, em relação aos dois atributos avaliados. No caso do cookie
$\mathrm{BG}_{50}$, que foi aceito por $80 \%$ dos provadores, para a aceitação global, sua aparência não foi aprovada pelos julgadores, o que comprova que a aparência dos alimentos tem grande influência na aceitação de novos produtos (Sharma \& Chauhan 2002).

\section{Composição centesimal da fração gérmen com pe- ricarpo de milho}

A fração GPM apresentou teores elevados de lipídios (aproximadamente 20\%) e de fibra alimentar (cerca de 30\%) (Tabela 3), podendo ser considerada matéria-prima de alto teor de fibras, de acordo com a legislação vigente no Brasil (Brasil 1998). Em comparação com outras fontes alimentares, a fração GPM possui conteúdo de fibra maior que aquele do farelo de aveia e do farelo de arroz extrusado (18\% e 16\%, respectivamente) e menor que o do farelo de trigo (43\%) (Grasten et al. 2002). Quanto à concentração de proteína, o valor encontrado neste estudo (12\%) é compatível com a literatura (Brito et al. 2005, Naves et al. 2011).

\section{Composição centesimal dos biscoitos tipo cookie}

Observa-se que a umidade dos biscoitos foi reduzida com o aumento da substituição da farinha de trigo e da fécula de mandioca por GPM (Tabela 3), fato também observado em cookies elaborados com $12,5 \%$ a $50,0 \%$ de substituição de farinha de trigo e fécula de mandioca por farelo de arroz extrusado (Lacerda et al. 2009).

Constatou-se elevação significativa $(p<0,05)$ no teor de proteínas para o biscoito $\mathrm{BG}_{50}$, em relação

Tabela 3. Composição centesimal e valor energético de gérmen com pericarpo de milho (GPM) e dos biscoitos controle (BC) e com $40 \%\left(\mathrm{BG}_{40}\right)$ e $50 \%\left(\mathrm{BG}_{50}\right)$ da fração GPM, em substituição à farinha de trigo e à fécula de mandioca (Goiânia, GO, 2010).

\begin{tabular}{|c|c|c|c|c|}
\hline \multirow{2}{*}{$\begin{array}{l}\text { Componente } \\
\left(\mathrm{g} 100 \mathrm{~g}^{-1}\right)^{1}\end{array}$} & \multirow{2}{*}{ GPM } & \multicolumn{3}{|c|}{ Biscoito } \\
\hline & & $\mathrm{BC}$ & $\mathrm{BG}_{40}$ & $\mathrm{BG}_{50}$ \\
\hline Umidade & $8,00 \pm 0,03$ & $3,06 \pm 0,14 \mathrm{a}$ & $3,17 \pm 0,10 \mathrm{a}$ & $2,41 \pm 0,05 \mathrm{~b}$ \\
\hline Proteína $(\mathrm{Nx} 6,25)$ & $12,02 \pm 0,39$ & $6,76 \pm 0,26 b$ & $6,88 \pm 0,26 b$ & $7,76 \pm 0,24 a$ \\
\hline Lipídios & $17,74 \pm 0,33$ & $17,78 \pm 1,65 a$ & $18,30 \pm 0,19 a$ & $19,47 \pm 0,63 a$ \\
\hline $\mathrm{CHO}$ & 29,80 & 66,27 & 61,63 & 55,72 \\
\hline FAT & $28,90 \pm 1,90$ & $4,32 \pm 0,04 \mathrm{c}$ & $8,12 \pm 0,02 b$ & $12,40 \pm 0,01 a$ \\
\hline FS & $5,20 \pm 0,80$ & $0,26 \pm 0,03 c$ & $0,52 \pm 0,05 b$ & $1,07 \pm 0,03 a$ \\
\hline FI & $23,70 \pm 1,10$ & $4,11 \pm 0,06 \mathrm{c}$ & $7,61 \pm 0,04 b$ & $11,34 \pm 0,04 a$ \\
\hline Cinzas & $3,54 \pm 0,04$ & $1,82 \pm 0,01 \mathrm{~b}$ & $1,90 \pm 0,35 \mathrm{ab}$ & $2,24 \pm 0,27 a$ \\
\hline VET (kcal) & 327 & $452 a$ & $439 b$ & $429 b$ \\
\hline
\end{tabular}

${ }^{1}$ Os valores constituem médias \pm desvios-padrão de três repetições, exceto fibra alimentar total (FAT), fibra solúvel (FS) e fibra insolúvel (FI), analisadas em quatro repetições; carboidratos (CHO), estimados por diferença; e valor energético total (VET), estimado por meio dos fatores de conversão de 4; 4; e 9, para proteínas, carboidratos e lipídios, respectivamente (Merril \& Watt 1973). Em uma mesma linha, médias com letras iguais não apresentam diferenças significativas, pelo teste Tukey, a 5\%. 
ao $\mathrm{BC}$ e ao $\mathrm{BG}_{40}$ (Tabela 3). Os teores de proteína dos três biscoitos foram semelhantes aos constatados em biscoitos elaborados com farelo de arroz extrusado (Lacerda et al. 2009) e em biscoitos formulados com farinha de jatobá-do-cerrado e de jatobá-da-mata (Silva et al. 2001a), cujos valores variaram entre $6,36 \%$ e 7,56\%. Ressalta-se que o perfil de aminoácidos essenciais da fração gérmen com pericarpo de milho atende a $100 \%$ das necessidades humanas de aminoácidos (Naves et al. 2011). Portanto, a fração GPM pode agregar qualidade protéica a produtos destinados ao consumo humano, como os biscoitos tipo cookie.

Os teores de lipídios dos biscoitos $\mathrm{BG}_{40}$ e $\mathrm{BG}_{50}$ não diferiram significativamente daquele da formulação controle (Tabela 3). Enquanto a fração GPM

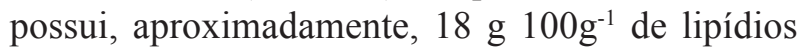
(Tabela 3), a farinha de trigo e a fécula de mandio-

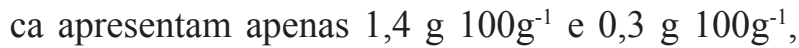
respectivamente (NEPA 2006). Apesar desta grande diferença entre os teores de lipídios do GPM e das farinhas substituídas, não houve diferença significativa entre os teores de lipídios dos cookies (Tabela 1), pois o GPM foi adicionado aos biscoitos $\mathrm{BG}_{40}$ e $\mathrm{BG}_{50}$ em proporções relativamente baixas $(17 \%$ e $21 \%$, respectivamente). Em relação aos dados da literatura, o teor de lipídios dos três cookies foi inferior ao constatado para biscoitos elaborados com $20 \%$

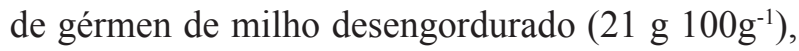
porque, na formulação deste biscoito, utilizou-se $24 \%$ de margarina (Rebolledo et al. 1999), concentração superior à utilizada no presente estudo $(20 \%)$.

A concentração de carboidratos dos cookies formulados com GPM foi menor, quando comparada ao cookie controle (Tabela 3). Em cookies, foi constatado que a adição de fibras resulta na redução de carboidratos (Silva et al. 2001a, Silva et al. 2001b).

Em relação à fibra alimentar, a adição da fração GPM ao biscoito elevou significativamente $(\mathrm{p}<0,05)$ os teores deste nutriente, especialmente no biscoito $\mathrm{BG}_{50}$. Assim, os cookies elaborados no presente estudo constituem alimentos de alto teor de fibras, por apresentarem concentração superior a $6{\mathrm{~g} 100 \mathrm{~g}^{-1}}^{-1}$ de fibra alimentar (Brasil 1998). Observa-se que a fibra da fração GPM é constituída, sobretudo, por fibra insolúvel (Tabela 3). Destaca-se a importância do consumo de alimentos com altos teores de fibras, em decorrência de suas numerosas propriedades funcionais e benefícios de seu consumo para a saúde (Brand-Miller 2002).
Nas últimas décadas, a ingestão de fibras, pela população brasileira, vem decrescendo consideravelmente. Dados da Pesquisa de Orçamentos Familiares (POF), realizada pelo Instituto Brasileiro de Geografia e Estatística (IBGE), em 2002/2003, apontam que as principais fontes de fibra da dieta têm contribuído cada vez menos com o total de calorias consumidas pelos brasileiros. Das calorias totais da dieta, as frutas, verduras e hortaliças correspondem a apenas 2,3\% (IBGE 2004). Assim, a fortificação de alimentos com ingredientes fontes de fibras constitui uma alternativa importante para aumentar o consumo de fibra pela população brasileira. No presente estudo, a adição da fração GPM ao biscoito tipo cookie, além de elevar o teor de fibras, reduziu o valor energético do produto (Tabela 3 ).

O teor de cinzas dos biscoitos também aumentou com a adição da fração GPM, que contém teores expressivos de cinzas (Tabela 3), indicando que esta fração contém quantidades consideráveis de minerais, o que pode incrementar a qualidade nutricional destes biscoitos. De fato, a fração GPM é rica em ferro $\left(5,33 \mathrm{mg} 100 \mathrm{~g}^{-1}\right)$ e zinco $\left(5,07 \mathrm{mg}_{100 \mathrm{~g}^{-1}}\right)$ (Castro et al. 2009), sendo fonte promissora de minerais para a alimentação humana, haja vista a importância do ferro na prevenção da anemia ferropriva, carência nutricional de elevada prevalência na população brasileira, e das funções enzimáticas e reguladoras do zinco, como parte do sistema antioxidante do organismo (Cozzolino 2007). Os valores de cinzas constatados no presente estudo são compatíveis com os relatados para biscoito formulado com $20 \%$ de gérmen de milho desengordurado (Rebolledo et al. 1999).

O VET estimado para os biscoitos com GPM foi semelhante aos encontrados na literatura, para este tipo de produto (Rebolledo et al. 1999, Silva et al. 2001a, Silva et al. 2001b, Lacerda et al. 2009), sendo observada redução significativa $(\mathrm{p}<0,05)$ do VET dos biscoitos $\mathrm{BG}_{40}$ e $\mathrm{BG}_{50}$, em relação ao $\mathrm{BC}$ (Tabela 3). Biscoitos adicionados de ingredientes fontes de fibra tendem a apresentar menor valor energético que os convencionais, em função de alterações nos teores dos macronutrientes. Uma alternativa para se reduzir ainda mais o valor energético do cookie elaborado no presente trabalho seria o emprego da fração GPM desengordurada nas formulações do cookie.

O GPM constitui-se em boa alternativa para as indústrias que têm interesse em desenvolver produtos mais saudáveis, ou até mesmo funcionais, pois, além 
de conferir altos teores de fibra alimentar, esta fração pode contribuir para a redução do valor energético dos produtos derivados. Neste sentido, é importante o desenvolvimento de processos e produtos a serem empregados na indústria moageira de milho, visando ao uso da fração GPM na alimentação humana e à consequente agregação de valor a esta matéria-prima.

\section{CONCLUSÕES}

1. A fração gérmen com pericarpo de milho contém teores apreciáveis de proteínas, lipídios e cinzas e altos teores de fibras alimentares.

2. O biscoito formulado com $17 \%$ da fração gérmen com pericarpo de milho $\left(\mathrm{BG}_{40}\right)$ apresentou boa aceitação e qualidade nutricional, sobretudo por conter alto teor de fibra alimentar.

3. O emprego da fração gérmen com pericarpo de milho, em produtos alimentícios, possibilita o aumento do teor de fibra alimentar e, eventualmente, a redução do valor energético dos produtos.

\section{REFERÊNCIAS}

ALEXANDER, R. J. Corn dry milling: process, products, and applications. In: WATSON, S. A.; RAMSTED, P. E. (Eds.). Corn: chemistry and technology. Saint Paul: American Association of Cereal Chemists, 1999. p. 351371.

ASSOCIATION OF OFICIAL ANALYTICAL CHEMISTS (AOAC). Official methods of analysis. 15. ed. Arlington: AOAC, 1990.

BLIGH, E. G.; DYER, W. J. A rapid method of total lipid extraction and purification. Canadian Journal of Biochemistry and Physiology, Ottawa, v. 37, n. 8, p. 911917, 1959.

BRAND-MILLER J. Carbohydrates. In: MANN, J.; TRUSWELL, S. Essentials of human nutrition. 2. ed. New York: Oxford University Press, 2002. p. 11-29.

BRASIL. Agência Nacional de Vigilância Sanitária. Portaria $n^{\circ} 27$ de 13 de janeiro de 1998. Aprova o regulamento técnico referente à informação nutricional complementar. 1998. Disponível em: <http://e-legis. anvisa.gov.br/leisref/public/showAct.php?id=97>. Acesso em: 27 out. 2009.

BRITO, A. B. et al. Avaliação nutricional do gérmen integral de milho para aves. Ciência Animal Brasileira, Goiânia, v. 6, n. 1, p. 19-26, 2005.
BUCK, J. S.; WALKER, C. E.; WATSON, K. S. Incorporation of corn gluten meal and soy into various cereal based food and resulting product functional, sensory and protein quality. Cereal Chemistry, Saint Paul, v. 64, n. 4, p. 264-268, 1987.

CASTRO, M. V. L. et al. Rendimento industrial e composição química de milho de alta qualidade protéica em relação a híbridos comerciais. Pesquisa Agropecuária Tropical, Goiânia, v. 39, n. 3, p. 233-242, 2009.

COLLI, C.; SARDINHA, F.; FILISETTI, T. M. C. C. Alimentos funcionais. In: CUPPARI, L. Guia de nutrição: nutrição clínica no adulto. 2. ed. Barueri: Manole, 2005. p. 71-87.

COZZOLINO, S. M. F. Biodisponibilidade de nutrientes. 2. ed. São Paulo: Manole, 2007.

FARIA, E. V.; YOTSUYANAGI, K. Técnicas de análise sensorial. Campinas: ITAL, 2002.

FOOD AND AGRICULTURE ORGANIZATION OF THE UNITED NATIONS (FAO). Amino-acid content of foods and biological data on proteins. Rome: FAO, 1970. (Nutritional studies, n. 24).

GIAMI, S. Y.; ACHINEWHU, S. C.; IBAAKEE, C. The quality and sensory attributes of cookies supplemented with fluted pumpkin (Telfairia occidentalis Hook) seed flour. Journal of the Science of Food and Agriculture, Oxford, v. 40, n. 3, p. 613-620, 2005.

GRASTEN, S. M. et al. Fibers with different solubility characteristics alter similarly the metabolic activity of intestinal microbiota in rats fed cereal brans and inulin. Nutrition Research, New York, v. 22, n. 12, p. 1435-1444, 2002.

INSTITUTO BRASILEIRO DE GEOGRAFIA E ESTATÍSTICA (IBGE). Pesquisa de orçamentos familiares 2002-2003: análise da disponibilidade domiciliar de alimentos e do estado nutricional no Brasil. Rio de Janeiro: IBGE, 2004.

JELTEMA, M. A.; ZABIK, M. E.; TIEL, L. J. Prediction of cookie quality from dietary fiber components. Cereal Chemistry, Saint Paul, v. 60, n. 3, p. 227-235, 1983.

LACERDA, D. B. C. L. et al. Qualidade de biscoitos elaborados com farelo de arroz extrusado em substituição à farinha de trigo e fécula de mandioca. Archivos Latinoamericanos de Nutrición, Caracas, v. 59, n. 2, p. 199-205, 2009.

MERRIL, A. L.; WATT, B. K. Energy value offoods: basis and derivation. Washington, DC: United States Department of Agriculture, 1973. 
NAVES, M. M. V. et al. Corn germ with pericarp in relation to whole corn: nutrient contents, food and protein efficiency, and protein digestibility-corrected amino acid score. Ciência e Tecnologia de Alimentos, Campinas, v. 31, n. 1, p. 264-269, 2011.

NÚCLEO DE ESTUDOS E PESQUISAS EM ALIMENTAÇÃO (NEPA). Tabela brasileira de composição de alimentos. Campinas: NEPA-Unicamp, 2006.

PAES, M. C. D. Aspectos físicos, químicos e tecnológicos do grão de milho. Sete Lagoas: Embrapa Milho e Sorgo, 2006. (Circular técnica, 75).

PALOMAR, L. S. et al. Optimization of a peanut-sweet potato cookie formulation. Food Science and Technology, London, v. 27, n. 4, p. 314-318, 1994.

REBOLLEDO, M. A.; SANGRONIS, E.; BARBOSACÁNOVAS, G. V. Evaluación de galletas dulces enriquecidas con germen de maíz y fibra de soya. Archivos Latinoamericanos de Nutrición, Caracas, v. 49, n. 3, p. 253-259, 1999.

SHARMA, H. R.; CHAUHAN, G. S. Effects of stabilized rice bran: fenugreek blends on the quality of breads and cookies. Journal of Food Science and Technology, Mysore, v. 39, n. 3, p. 225-233, 2002.
SILVA, M. R. et al. Utilização tecnológica dos frutos de jatobá-do-cerrado e de jatobá-da-mata na elaboração de biscoitos fontes de fibra alimentar e isentos de açúcares. Ciência e Tecnologia de Alimentos, Campinas, v. 21, n. 2 , p. 176-182, 2001a.

SILVA, M. R.; BORGES, S.; MARTINS, K. A. Avaliação química, física e sensorial de biscoitos enriquecidos com farinha de jatobá-do-cerrado e de jatobá-da-mata como fonte de fibra alimentar. Brazilian Journal of Food Technology, Campinas, v. 4, n. 73, p. 163-170, 2001 b.

SOARES JÚNIOR, M. S. et al. Qualidade de biscoitos formulados com diferentes teores de farinha de amêndoa de baru (Dipteryx alata Vog.). Pesquisa Agropecuária Tropical, Goiânia, v. 37, n. 1, p. 51-56, 2007.

WILSON, M. W. Proteins of the kernel. In: WATSON, S. A.; RAMSTED, P. E. (Eds.). Corn: chemistry and technology. Saint Paul: American Association of Cereal Chemists, 1999. p. 273-309. 